\title{
Social Aspect of Student's Language Learning Style in Differentiated ESP Instruction
}

\author{
Sofiya Nikolaeva ${ }^{1}$, Oksana Synekop ${ }^{2, *}$ \\ ${ }^{1}$ Department of Foreign Languages Methodology Teaching and Information and Communication Technologies, Kyiv National \\ Linguistic University, Kyiv, Ukraine \\ ${ }^{2}$ Department of English for Engineering, Faculty of Linguistics, National Technical University of Ukraine "Igor Sikorsky Kyiv \\ Polytechnic Institute", Kyiv, Ukraine
}

Received June 16, 2020; Revised July 20, 2020; Accepted August 25, 2020

\section{Cite This Paper in the following Citation Styles}

(a): [1] Sofiya Nikolaeva, Oksana Synekop, "Social Aspect of Student's Language Learning Style in Differentiated ESP Instruction," Universal Journal of Educational Research, Vol. 8, No. 9, pp. 4224-4233, 2020. DOI: 10.13189/ujer.2020.080949.

(b): Sofiya Nikolaeva, Oksana Synekop (2020). Social Aspect of Student's Language Learning Style in Differentiated ESP Instruction. Universal Journal of Educational Research, 8(9), 4224-4233. DOI: 10.13189/ujer.2020.080949.

Copyright $\bigcirc 2020$ by authors, all rights reserved. Authors agree that this article remains permanently open access under the terms of the Creative Commons Attribution License 4.0 International License

\begin{abstract}
The study aims to investigate the possibility of using the Belbin Self-Perception Inventory (SPI) for the actualization of the social aspect of the language learning style in the differentiated English for specific purposes (ESP) learning of information technology (IT) students so as to determine the students' and teachers' attitudes to the use of Belbin's roles in the differentiated ESP instruction. To achieve the outlined aim, a mixed research design was employed which involved 180 university IT students and 10 teachers. For data collection we used the Belbin's SPI, students' self-assessment survey and ESP teachers' survey. The results showed that the students' team and functional roles were evident in each group, irrespective of the number of students in it. Communicative roles were found to be an integral part of functional, team, and social roles. Various interaction patterns were defined for students' functional roles. The findings suggested that in the context of social relations and the roles, the subject of a conversation, communicative behavior, professional knowledge, experience, and language potential of the interlocutors are different and reflect the specifics of the situation. To improve the students' communicative skills, three stages of role learning were suggested. The optimal group size for the differentiated ESP instruction was defined. The Belbin's roles were found suitable for groups of students with different English language proficiency levels. This study showed that the use of Belbin's approach to actualization of the social aspect of the language learning style in the differentiated ESP instruction can be
\end{abstract}

effectively used in teaching IT students at university.

Keywords Differentiated ESP Instruction, Social Aspect, Language Learning Style, IT Students

\section{Introduction}

With the development of the information technology (IT) as the most promising industry in Ukraine, there is a need for training future IT professionals who are not only competent in the area of their knowledge but also fluent in English for specific purposes (ESP). Among the main challenges in ESP teaching at technical universities in Ukraine are an insufficient number of learning hours for ESP instruction, uneven language proficiency of students, unequal number of learners in groups. In this regard, the problem arises of improving the quality of training of IT specialists, which necessitates the identification of new priorities in teaching. One of the dominant priorities is taking into account the differences in students' English language proficiency levels and language learning styles. Thus, the optimization of the process of effective English language acquisition by the IT students should be relied on the actualization of the differentiated ESP instruction.

The concept of language learning style is the key tool for creating personality profiles, and, therefore, a tool for understanding what kind of teaching is the most 
appropriate for a student. The language learning style is considered to be "one of the factors that helps determine how - and how well - our students learn foreign language" $[1$, p. 1$]$, in other words "the manner in which individuals choose to or are inclined to approach a learning situation has an impact on performance and achievement of learning outcomes" [2, p. 420]. As the learning style is "a multidimensional phenomenon" [1, p. 1], a learner reflects different style dimensions. In addition to the dominant cognitive aspect as one that "creates the effect of immersing into language learning style" [3, p. 40-41] with the focus on learners' perception $[4,5]$ and processing of information $[6$, p. $124 ; 7 ; 3]$, the social aspect can also be regarded as an important aspect of the language learning style.

In fact, the social aspect is based on social interaction that implies a rational and conscious exchange of information, experience, and skills in the activity of learners and in their mutual influence on each other. A man by nature is a social being that satisfies his or her needs through communication and interaction with other people. As a means of communication, language consolidates participants of communication process, makes their activity possible. In the process of socialization in the professional environment, IT students acquire socio-cultural experience; get knowledge about using a variety of linguistic means, the features of communicative interactions, strategies of conducting a conversation; develop the skills of informing, requesting, agreeing or disagreeing, encouraging and supporting an interlocutor in communication. All that will allow the future IT professionals to successfully communicate in the professional environment.

The IT professionals with the aforementioned skills and abilities are necessary for any IT company that wants to be successful on the IT market. According to the researchers [8], maximization of software quality depends on both technological and non-technological issues of software development, the solution of which relies on differences in individual performance [8, p. 146]. Among non-technological issues - "the soft side of computer science" [9, p. 147], soft skills [10, 11], "soft factors" [12] - the main one is the social interaction through communication that provides an effective exchange of information to formulate and achieve the strategic goals. Boehm [13] focuses on the fact that "personnel attributes and human relations activities provide by far the largest source of opportunity for improving software productivity" [p. 666].

As a rule, a team in a company is a manifestation of the social interaction of employees, which can be realized in the form of cooperation, competition or conflict. It is known that IT company employees work on software development projects in teams, where the responsibilities between the participants are clearly shared. In this regard, different aspects of organizing teams in an effective way have been studied. For instance, with the aim of defining the benefits for global software development teams, Hargreaves and Damian [14] learned the models of military teamwork. Having analyzed the military model of building teams to adopt it to software subculture, they found the positive traits in that "the vertical chain of command and a visible hierarchy simplifies communication between coworkers; informal communication is also highly influenced by this subculture - slang, jokes and topics commonly discussed within the military environment contribute to creating cohesive teams; there is a consistent level of personal accountability for other team members" [14]. Hoegl and Gemuenden [15] outlined the factors (communication, coordination, balance of member contributions, mutual support, effort) that influence software team performance. Samarasinghe and Samarasinghe [16] considered the factors influencing team performance in software development projects, among which are communication, cohesion, trust, value diversity and coordination of expertise. Pinto and Pinto [17] emphasized the importance of communication that is "the vehicle through which personnel from multiple functional areas share information that is so critical to the successful implementation of projects" [p. 201]. At the center of all the mentioned studies is the interaction of personnel in the communication process to carry out joint actions in teams towards the achievement of one strategic goal. Thus, the social aspect in teams is considered significant.

In the context of teaching foreign languages, the literature seems to suggest that there is a potential possibility of using the social aspect for improving learning. According to Oxford [1], within the area of language learning styles, each individual reflects social style dimensions and can be either an extrovert or introvert [1, p. 3]. "By definition, extroverts gain their greatest energy from the external world. They want interaction with people and have many friendships, some deep and some not. In contrast, introverts derive their energy from the internal world, seeking solitude and tending to have just a few friendships, which are often very deep" [1, p. 5]. Similarly, in the context of social aspect Rezler and Rezmovic [18] in the Learning Preference Inventory outline two types of learners: individual and interpersonal. Learner's preferences for social interaction during the learning process are taken into account by Reichmann and Grasha's [19]. In their Student Learning Style Scale, they differentiate students in accordance with the type and level of interaction including collaborative / competitive, and participant / avoidant.

In our opinion, teaching a foreign language to the future IT professionals should be as close as possible to the professional environment. Belbin's [20, 21] approach, as contrasted to other suggested methods, is of special interest to learn foreign language for several reasons. Firstly, this approach is widely used in software development projects that are increasingly popular now 
and need employees with various skills. In many ways, software development teams face challenges similar to those faced by language learning teams at technical university. Working together in a team in various situations, IT professionals as well as language learners at technical university can perform different roles and follow different patterns of behavior. Secondly, Belbin's [20,21] approach allows analyzing characteristics of an individual in terms of his / her social interaction, enables to determine the strengths and weaknesses of IT student's behavior, and adapt his / her behavior to the needs of the future professional field. Thirdly, the approach promotes the development of professional communicative foreign language competencies (in listening, speaking, reading and writing). Finally, this approach helps to improve social interaction between participants of communication in various situations of the IT field and to get the experience of carrying out software development projects.

In view of this, it is evident that the awareness of the social aspect of language learning style promotes the dynamics of communication through the exchange of information, experience, and knowledge between interlocutors in IT business. Thus, the main focus of the study is searching for the ways of transferring the experience of IT companies, particularly, in the use of Belbin's [20] questionnaire, to differentiated ESP instruction at university in order to enhance the communicative abilities of students.

In the interests of enhancing the efficiency of ESP learning within the context of the differentiated ESP instruction, the aims of this article are:

1) to investigate the possibility of using the Belbin Self-Perception Inventory (SPI) for the actualization of social aspect of the language learning style in the differentiated ESP instruction of IT students;

2) to find out the students' and teachers' attitudes to the use of Belbin's roles in the differentiated ESP instruction.

\section{Method}

\subsection{Research Design}

In this research we studied the specifics of students' language learning styles through the roles they performed and the communicative tasks they solved when performing those roles. We analyzed the ways in which students' functional and team roles are related to their social roles and how teachers can create education environment with the maximum consideration of individual features of learners. Thus, we employed the mixed research design which aimed to collect and analyze quantitative data from IT students' answers to Belbin's [20] questionnaire and qualitative data from students' and teachers' answers to the surveys. For our purposes we used the first version of the Belbin's questionnaire suggested in 1981. Throughout this study, SPI, Belbin's [20] questionnaire, was used to define the students' functional and team roles and also their oriented type of activity. Using the mentioned questionnaire, the following students' roles in teams were defined (the names of the roles were suggested by Belbin [20, 21]): a Plant, a Resource Investigator, a Co-ordinator, a Shaper, a Monitor Evaluator, a Teamworker, an Implementer and a Completer Finisher. Eight roles in the first version of Belbin's questionnaire [20] were used in this research.

After that various communicative situations, role plays and projects were introduced in the process of the differentiated ESP instruction to observe how Belbin's [20] approach works for enhancing the quality of language learning process. For this purpose, the students were divided into groups with unequal numbers of participants (from two to eight). Then, the mechanisms of language learning styles formation suggested by Leaver [22] and Kondrashihina [23] were used which implied three stages. First, at the stage of adaptation IT students performed their dominant roles and worked with peers. Then, at the stage of development, the IT students performed auxiliary roles to realize their potential abilities through the use of preferred language learning style. This gave IT students an opportunity to master additional features of behavior and interaction patterns in communication. Finally, at the third stage of variation and improvement of the language learning styles, the IT students varied their roles improving their ability to work in groups with unequal numbers of participants and communicate with different partners.

After such differentiated ESP instruction an anonymous self-assessment survey of IT students and a survey of ESP teachers were conducted to find out the students' and teachers' attitudes to the use of Belbin's $[20,21]$ roles in the differentiated ESP instruction.

\subsection{Research Participants}

During 2017-2019 academic years, the differentiated ESP instruction with the use of functional and team roles was suggested to IT students of the Institute of Physics and Technology, Faculty of Informatics and Computer Science of National Technical University of Ukraine "Igor Sikorsky Kyiv Polytechnic Institute". The participants were mostly males, aged from 20 to 22 years. The total number of the third and fourth-year IT students who participated in the study was 180 . The groups consisted of different numbers of students who volunteered to take part in the study. There were four groups of the third-year students, including $18-25$ students (90 students in total), and nine groups of the fourth-year students, consisting of 3 - 16 students (90 students in total). Also 10 ESP teachers were involved in this research. The students' English language proficiency level ranged from B1 to B2 according to the CEFR scale. 


\subsection{Research Instruments and Procedures}

In the study we used printed copies of the Belbin SPI, a self-assessment survey of IT students and a survey of ESP teachers. The research was conducted at three stages. At the first stage the Belbin [20] SPI was used for defining the dominant roles. The questionnaire consisted of seven separate blocks each containing eight questions or assumptions that a student could or could not agree with. The maximum number of points for each block was 10 and they had to be distributed between the block statements that a student agreed with. No more than 3 or 4 assumptions were allowed in the block. If the student agreed to one of the assumptions only, he / she could give it all 10 points. The minimum number of points assigned to one assumption was 2. The total number of points for the whole test was 70 . The questionnaire took 15-20 minutes to complete. One person could perform more than one role in the team.

At the second stage, the third and fourth-year IT students were involved in the differentiated ESP instruction. The communicative situations, projects and role plays were suggested. Among the key projects for the third and fourth-year students were "Creating the Web site", "Privacy vs. Security", "Cyber Warfare", and "Software Testing". Also the role plays "Job Searching" and "Biometrics technologies" were added to the list of projects.

At the third stage, an anonymous survey for the self-assessment of IT students was offered which contained six closed questions:

1. Do you think that the knowledge about social interaction skills will help you in your work in the IT field?
a. Yes
b. No

2. Did the knowledge about the behavior features of your dominant roles help you process of learning ESP? in the

a) evaluate the social abilities (yes, no, I don't know)

b) interact properly with other fellow students

(yes, no, I don't know)

c) organize your activities (yes, no, I don't know)

3. Did the activities (communicative situations, role plays, projects) where you had to perform certain roles help you improve communicative skills in in the process of learning ESP?
a) listening
b) speaking
c) reading
d) writing

4. Did you like to experiment with different roles?
a. Yes
b. No

5. What interaction pattern(s) did you prefer most in the suggested activities? Several answers can be circled.
a. "Pairs"
b. "Small groups"
c. "Large groups"

6. Do you think that differentiation according to roles and foreign language proficiency levels is important for participating in projects, role plays, communicative situations?
a. Yes
b. No

The anonymous survey for ESP teachers that contained four questions was used. The questions were as follows:

1. Do you think that the knowledge about social interaction skills will help IT students improve their professional language communicative competence?
a. Yes
b. No

2. Do you think that students should experiment with different roles?
a. Yes
b. No

3. Do you think that differentiation according to roles and foreign language proficiency levels is important for participating in projects, role plays, communicative situations?
a. Yes
b. No

4. How many students should a group / team in an ESP course consist of? Several answers can be circled.

$$
\begin{array}{lllllll}
2 & 3 & 4 & 5 & 6 & 7 & 8
\end{array}
$$

\subsection{Data Analysis}

Data analysis of the results was conducted at two stages. The first stage involved examining the data of Belbin's [20] questionnaire with the aim to define the roles of the IT students for the actualization of social aspect of the language learning style in the differentiated ESP instruction. At the second stage, the teacher observed the differentiated ESP learning process. At the third stage, we analyzed data from the survey of IT students' self-assessment and the survey of ESP teachers to find out the students' and teachers' attitudes to the use of Belbin's roles in the differentiated ESP instruction. 


\subsection{Results}

Testing 90 third-year IT students (Table 1) for determining the team roles has shown that $76.66 \%$ of them can perform the role of an Implementer, $31.11 \%$ - a Completer Finisher, $42.22 \%$ - a Shaper, $42.22 \%$ - a Co-ordinator, 37.77\% - a Teamworker, $18.88 \%$ - a Resource Investigator, $43.33 \%$ - a Plant, 32.22\% - a Monitor Evaluator. Most students (Groups 1-4) can perform the role of hard workers, a smaller number of students - the roles of leaders (Groups 1,2 and 3) and intellectuals (Group 4). The role of negotiators can be performed by the least number of students. Taking into account the fact that the students can perform several roles, the balance in distribution of action-oriented, people-oriented and thinking-oriented roles can be achieved.

Table 1. Testing results of third-year IT students according to the Belbin SPI

\begin{tabular}{|c|c|c|c|c|c|c|c|c|c|}
\hline \multirow{3}{*}{ Group } & \multirow{3}{*}{$\begin{array}{l}\text { Number } \\
\text { of students }\end{array}$} & \multicolumn{2}{|c|}{ Hard workers } & \multicolumn{2}{|c|}{ Leaders } & \multicolumn{2}{|c|}{ Negotiators } & \multicolumn{2}{|c|}{ Intellectuals } \\
\hline & & Implementer & Completer Finisher & Shaper & Co-ordinator & Teamworker & $\begin{array}{c}\text { Resource } \\
\text { Investigator }\end{array}$ & Plant & Monitor Evaluator \\
\hline & & \multicolumn{3}{|c|}{ Action-oriented } & \multicolumn{3}{|c|}{ People-oriented } & \multicolumn{2}{|c|}{ Thinking-oriented } \\
\hline G1 & 25 & 18 & 9 & 13 & 10 & 11 & 6 & 12 & 8 \\
\hline $\mathrm{G} 2$ & 18 & 16 & 6 & 9 & 6 & 5 & 2 & 8 & 5 \\
\hline G3 & 24 & 19 & 6 & 9 & 13 & 10 & 1 & 8 & 9 \\
\hline G4 & 23 & 16 & 7 & 7 & 9 & 8 & 8 & 11 & 7 \\
\hline \multirow{2}{*}{ Total } & 90 & 69 & 28 & 38 & 38 & 34 & 17 & 39 & 29 \\
\hline & $\%$ & 76.66 & 31.11 & 42.22 & 42.22 & 37.77 & 18.88 & 43.33 & 32.22 \\
\hline
\end{tabular}

Table 2. Testing results of fourth-year IT students according to the Belbin $(1981,2010)$ SPI

\begin{tabular}{|c|c|c|c|c|c|c|c|c|c|}
\hline \multirow{3}{*}{ Group } & \multirow{3}{*}{$\begin{array}{l}\text { Number } \\
\text { of } \\
\text { students }\end{array}$} & \multicolumn{2}{|c|}{ Hard workers } & \multicolumn{2}{|c|}{ Leaders } & \multicolumn{2}{|c|}{ Negotiators } & \multicolumn{2}{|c|}{ Intellectuals } \\
\hline & & Implementer & Completer Finisher & Shaper & Co-ordinator & Teamworker & Resource Investigator & Plant & Monitor Evaluator \\
\hline & & \multicolumn{3}{|c|}{ Action-oriented } & \multicolumn{3}{|c|}{ People-oriented } & \multicolumn{2}{|c|}{ Thinking-oriented } \\
\hline G1 & 16 & 10 & 9 & 6 & 6 & 9 & 4 & 4 & 3 \\
\hline $\mathrm{G} 2$ & 15 & 11 & 5 & 7 & 9 & 4 & 4 & 7 & 4 \\
\hline G3 & 3 & 2 & & 3 & 2 & & 1 & & 3 \\
\hline G4 & 5 & 5 & 3 & 2 & & 2 & & & 3 \\
\hline G5 & 8 & 5 & 3 & 1 & 4 & 5 & 4 & 2 & 4 \\
\hline G6 & 15 & 8 & 4 & 8 & 10 & 6 & 6 & 4 & 5 \\
\hline G7 & 11 & 5 & 1 & 7 & 5 & 5 & 1 & 2 & 6 \\
\hline G8 & 9 & 4 & 2 & 6 & 3 & 4 & 4 & 4 & 1 \\
\hline G9 & 8 & 5 & 0 & 3 & 4 & 3 & 4 & 3 & 4 \\
\hline \multirow{2}{*}{ Total } & 90 & 55 & 27 & 43 & 43 & 38 & 28 & 26 & 33 \\
\hline & $\%$ & 61.1 & 30 & 47.77 & 47.77 & 42.22 & 31.11 & 28.88 & 36.66 \\
\hline
\end{tabular}


Among 90 fourth-year IT students (Table 2), 61.1\% can perform the role of an Implementer, $30 \%$ - of a Completer Finisher, $47.77 \%$ - of a Shaper, $47.77 \%$ - of a Co-ordinator, $42.22 \%$ - of a Teamworker, $31.11 \%$ - of a Resource Investigator, $28.88 \%$ - of a Plant, $36.66 \%$ - of a Monitor Evaluator.

In Groups 1, 2, 4, most participants can perform the role of hard workers, in Groups 3, 6, 7 and 8 - the role of leaders, in Group 5 - the role of negotiators. In Group 9 the roles of leaders, negotiators and intellectuals are balanced. In addition, in each group there are students who can perform action-oriented, people-oriented and thinking-oriented roles.

The analysis of the answers of the students' self-assessment survey showed that both the third-year students $(95 \%)$ and fourth-year students $(97 \%)$ believe that social interaction skills will help them in their future professional activity and only a small percentage of respondents $(5 \%$ of the third-year and $3 \%$ of the fourth-year students) think that this will not be useful to them. It is evident that most of the students assume that the knowledge about the behavior features of the roles helped them evaluate their social abilities (70\% of the third-year and $85 \%$ B of the fourth-year students), interact properly with peers $(80 \%$ of the third-year and $90 \%$ of the fourth-year students), organize their activities ( $76 \%$ of the third-year and $67 \%$ of the fourth-year students) in the process of ESP learning. Using a role format for communicative situations, role plays, projects, helped the students to improve their communicative skills in listening $(85 \%$ of the third-year and $95 \%$ of the fourth-year students), speaking ( $100 \%$ of the third-year and $98 \%$ of the fourth-year students), reading ( $80 \%$ of the third-year and $83 \%$ of the fourth-year students), writing $(70 \%$ of the third-year and $55 \%$ of the fourth-year students). Also, experimenting with different roles was found useful by most respondents $(75 \%$ of the third-year and $70 \%$ of the fourth-year students). The most preferred interaction patterns were "small groups" $(80 \%$ of the third-year and $90 \%$ of the fourth-year students), "pairs" ( $43 \%$ of the third-year and $50 \%$ of the fourth-year students) and "large groups" $(60 \%$ of the third-year and $55 \%$ of the fourth-year students). Also, $93 \%$ and $95 \%$ of third and fourth-year students, respectively, thought that differentiation according to roles and foreign language proficiency levels was important for participating in projects, role plays and communicative situations.

Most of the ESP teachers were convinced that social interaction skills helped IT students improve their professional language communicative competence $(100 \%)$; role playing was useful and students should experiment with their roles (85\%); differentiation according to roles and foreign language proficiency levels was important for participating in projects, role plays and communicative situations $(100 \%)$. Also, the majority of them thought that the most appropriate sizes of groups / teams in ESP teaching were two $(55 \%)$, three $(86 \%)$, four $(87 \%)$, five
(90\%) students.

\section{Discussion}

While studying the social aspect of the learning style, some important problems have been addressed, connected with the performance of social roles in teaching and learning ESP. Roles are necessary attributes of the communicative situations in the context of the IT field. The first question was focused on the differentiation of the IT students according to various types of roles, defining the tasks they performed, the features of behavior and communication. The results show that students' team and functional roles are evident in each of the groups irrespective of the number of students in them. A team role "refers to a tendency to behave, contribute, and interrelate with others at work in certain distinctive ways" [21, p. 24]. A functional role relates to "the job demands that a person has been engaged to meet by supplying the requisite technical skills and operational knowledge" [21, p. 24]. Belbin's functional roles are related to team roles, e.g. hard workers relate to an Implementer and a Completer Finisher; leaders - to a Shaper and a Co-ordinator; negotiators - to a Teamworker and a Resource Investigator; intellectuals - to a Monitor Evaluator and a Plant [21]. These roles are intersected and focus on a specific type of activity action-oriented, people-oriented and thinking-oriented.

The types of student's tasks, the features of student's behavior and communication corresponding to the team roles are presented in Table 3. Generally, hard workers prefer to realize plans and solve analytical tasks. Due to introspection and reflection which are specific to their behavior, hard workers are able to think about actions, examine and modify the objects, self-evaluate at run-time. They are rather introverted, prefer performing tasks alone and employ the "pairs" or "small groups" interaction patterns in the process of communication. The examples of corresponding social roles are a software tester and a programmer.

The typical tasks of leaders are decision-making; strategic planning; considering advantages and disadvantages of issues, delegating tasks to others. Leaders are communicative, basically extroverts. Thus, they prefer maximally stimulating environment and the "large groups" interaction pattern, for example, an IT-director can be a representative of the functional role of "leaders".

Among the tasks of negotiators are the dynamic development of contacts within and outside the team or company, thinking strategically and finding different solutions. They are constructive, sociable, capable of listening and influencing others, mostly extroverted, prefer the "large groups" interaction pattern. The examples of corresponding social roles are a project manager and a team leader. 
Table 3. Characteristics of IT students' roles, types of tasks, features of behavior and interaction patterns in communication based on Belbin's (1981, 2010) SPI

\begin{tabular}{|c|c|c|c|c|c|c|}
\hline $\begin{array}{c}\text { Functional } \\
\text { roles }\end{array}$ & Types of tasks & $\begin{array}{c}\text { Features of behavior, interaction patterns } \\
\text { in communication }\end{array}$ & Social roles & Team Roles & Type of activity & $\begin{array}{c}\text { Communicative } \\
\text { roles }\end{array}$ \\
\hline Hard workers & $\begin{array}{l}\text { realizing plans; solving analytical } \\
\text { tasks }\end{array}$ & $\begin{array}{l}\text { introspective and reflective, rather } \\
\text { introverted; working alone, prefer "pairs" or } \\
\text { "small groups" interaction patterns }\end{array}$ & $\begin{array}{l}\text { Software tester, Programmer, } \\
\text { Front- and Back-end engineers }\end{array}$ & $\begin{array}{l}\text { Implementer, } \\
\text { Completer Finisher }\end{array}$ & \multirow[t]{2}{*}{ Action-oriented } & \multirow{5}{*}{$\begin{array}{l}\text { Sender / speaker, } \\
\text { writer (active) \& } \\
\text { Receiver / } \\
\text { listener, reader } \\
\text { (passive) }\end{array}$} \\
\hline \multirow{2}{*}{ Leaders } & \multirow{2}{*}{$\begin{array}{c}\text { decision-making; strategic } \\
\text { planning; considering pros and } \\
\text { cons of issues; delegating tasks to } \\
\text { other people }\end{array}$} & \multirow{2}{*}{$\begin{array}{l}\text { communicable, mostly an extrovert; } \\
\text { prefer "large groups" interaction pattern }\end{array}$} & \multirow{2}{*}{$\begin{array}{l}\text { IT-director, } \\
\text { Product owner }\end{array}$} & Shaper, & & \\
\hline & & & & Co-ordinator & \multirow[b]{2}{*}{ People-oriented } & \\
\hline Negotiators & $\begin{array}{l}\text { developing contacts within and } \\
\text { outside the team / company; } \\
\text { experimenting with different } \\
\text { strategies }\end{array}$ & $\begin{array}{l}\text { able to listen, constructive, sociable, capable } \\
\text { of influencing others, mostly extroverted; } \\
\text { prefer "large groups" interaction pattern }\end{array}$ & Project manager, Scrum master & $\begin{array}{l}\text { Teamworker, } \\
\text { Resource } \\
\text { Investigator }\end{array}$ & & \\
\hline Intellectuals & $\begin{array}{l}\text { analyzing information with } \\
\text { particular attention to details, } \\
\text { minimizing risks, solving } \\
\text { analytical tasks }\end{array}$ & $\begin{array}{l}\text { individualist, critical, thoughtful, mostly } \\
\text { introverted; interaction pattern "pairs" or } \\
\text { "small groups" }\end{array}$ & System analyst & $\begin{array}{l}\text { Monitor Evaluator, } \\
\text { Plant }\end{array}$ & Thinking-oriented & \\
\hline
\end{tabular}


Intellectuals can analyze information, minimize risks, are attentive to details, good at solving analytical tasks. They are individualistic, critical, and thoughtful. By nature, intellectuals are mostly introverted. So, they prefer minimally stimulating environment and interaction patterns of "pairs" or "small groups". A system analyst is an example of the corresponding social role.

In addition to social and functional roles in the process of communication, Formanovskaya [24] mentions communicative roles that determine the position of communicators [24, p. 152]. These roles are a sender/a speaker / a writer, who initiates a message, and a receiver / a listener / a reader, who accepts the message of an interlocutor. The communication occurs when the exchange of messages between interlocutors performing communicative roles takes place. The participants of communication can perform both an active and a passive role. Thus, the IT students' communicative roles do not have functional, social or team limitations, which means that communicative roles are superimposed on any functional, social or team roles and the participants of a conversation can both initiate a message and act as a listener in any communicative situation.

The social relations of the interlocutors are arranged in two coordinates - the vertical "higher - equal - lower" according to a status and a role, as well as the horizontal "insider - outsider" [24, p. 57]. In the coordinate system of the social relationships in an IT project, for instance, a business owner is higher vertically; a front-end and a back-end have an equal status in a team, a tester is lower than a business owner in status; horizontally, "insiders" are all employees that participate in a software development project, "outsiders" are clients. Taking into consideration the system of coordinates of social relations and the Belbin's [20] roles, it should be noted that the subject of a conversation, communicative behavior, professional knowledge, experience, language (vocabulary, grammar, and stylistics) potential of the interlocutors will be different and will correspond to the specifics of the situation.

The second question concerned the appropriate size of the groups of IT students for different ESP purposes. As defined by Salas, Dickinson, Converse, and Tannenbaum [25], a human team is "a distinguishable set of two or more people who interact dynamically, interdependently, and adaptively towards a common and valued goal / objective / mission" [25, p. 4]. Belbin [20] suggests eight roles in his first version of the questionnaire which we used in this research. Thus, the teams can include two to eight students depending on the project. In ESP teaching, two team members are not always enough for a project, but acceptable for communicative situations not related to a particular project, for example, a communicative situation where the students need to discuss the benefits and drawbacks of automated and manual testing. In this case one of the students performs the role of a software tester and the other - the role of a student or another software tester. Teams of two to eight members are appropriate if the roles are balanced. In ESP learning the acceptable number is two, three, four, or five members in a group. In such teams the contribution of each student is obvious, the actions of team members can be controlled, and there is no chaos.

Belbin [21] mentions acceptable combinations of different roles for solving different tasks: a Plant relates well with Co-ordinators, Teamworkers; a Monitor Evaluator works best with Co-ordinators, Implementers; a Resource Investigator performs well with Implementers, Teamworkers, and Completer Finishers; an Implementer prefers working with Co-ordinators, Monitor Evaluators, Resource Investigators, Completer Finishers; a Completer Finisher gains benefit from Resource Investigators, Plants, and Shapers; a Shaper can successfully cooperate with Resource Investigators, Teamworkers, Completer Finishers; a Co-ordinator works best with Teamworkers, Implementers; a Teamworker can co-work with Plants [21, p. 64-71]. Using such groups of IT students gives an opportunity to solve problems, make quick decisions, avoid conflicts, and achieve consensus in communication.

The third question was linked with the reasons of changing the students' roles. Generally, learning styles operate on a continuum or on multiple, intersecting continua [1, p. 3]. This idea works in the Belbin [21] SPI when one person can perform more than one role. For example, according to Belbin's questionnaire, one of the students in our survey can perform the role of an Implementer (12 points), a Completer Finisher (14 points) and a Monitor Evaluator (12 points). The first two roles relate to hard workers, the last one refers to intellectuals. This implies that the student is action-oriented and thinking-oriented. The mentioned roles are dominant for him and he can balance them freely in solving different tasks. In this case the functional roles of leaders and negotiators are considered as auxiliary roles of the IT student.

According to Belbin [21], "role learning is what occurs when individuals participate in education on team skills" [21, p. 28]. He also adds that "by recognizing the roles of others and by becoming aware of the range of roles that are available, along with those that are not, people learn to modify their behavior to take account of the situation" [21, p. 28]. Undoubtedly, it is reasonable to use role playing to expand the range of roles that students can perform. It will allow students not only to experiment and learn to adapt their behavior to certain roles but also to broaden their interaction patterns ("large groups", "pairs", small groups"), develop and improve their communicative skills in the IT field. For this purpose, at the first stage of learning ESP, students perform roles that are familiar to them or dominant ones; at the second stage, they adapt their behavior and master the roles that are new to them; at the 
third stage, students vary different behavioral patterns.

The fourth question related to the consideration of different foreign language proficiency levels of students (B1, B2). Differentiation of IT students according to the Belbin's roles implies the formation of groups in which the students' English language proficiency levels in the group / team can be the same or different. If they are different, it is important that the teacher assigns roles to students with consideration of their language competence. Students with B1 English language proficiency level should be provided by scaffolding (additional phrases, descriptions).

While this study highlighted the importance of the social aspect of learning style and its role in the differentiated ESP instruction, a potential limitation should be mentioned. According to the results of our research, a proper combination of students' team roles ensures perfect social interaction in the communication process, and therefore provides the effectiveness of a project or problem solving in any professional situation. However, both in software development projects in IT business and in language learning at university, employees and IT students can be involved in situations that require knowledge and use of strategies and tactics for finding a consensus and resolution of conflicts. Thus, further study is needed of such strategies and tactics which can be used by each team role in the process of differentiated instruction.

\section{Conclusions}

In conclusion, teaching IT students should be as close as possible to the real conditions of the professional environment, where, in addition to the necessary professional knowledge and skills, they should be able to work in a team, which is vital for the success of not only a particular project, but also the company as a whole. In view of this, the differentiated ESP instruction based on the language learning style specifics and the students' English language proficiency levels may be highly efficient at university. The awareness of the social aspect of language learning style ensures the dynamics of communication through the exchange of information, experience, and knowledge between interlocutors. Belbin's $[20,21]$ approach, applied widely in software development projects, has been used for differentiation of students by the functional and team roles. During the study we analyzed functional, team, social, and communicative roles, behavior of students while performing the roles; identified interactive patterns; outlined the optimal team sizes in ESP learning. In addition, the stages of role learning, the features of forming teams consisting of students with different English language proficiency levels were defined, which may be useful in the differentiated ESP instruction for IT students at university.

\section{REFERENCES}

[1] R. L. Oxford. Language learning styles and strategies: an overview. Learning Styles \& Strategies, Oxford, GALA, 125,2003 . Online available from

http://web.ntpu.edu.tw/ language/workshop/read2.pdf .

[2] S. Cassidy. Learning Styles: An overview of theories, models, and measures. Educational Psychology, Vol. 24, No. 4, 419-444, 2004, doi.org/10.1080/0144341042000228834

[3] O. Synekop. Cognitive Aspect of Learning Style in Differentiated ESP Instruction for the Future IT Specialists. Advanced Education, Vol. 10, 40-47, 2018. doi.org/10.20535/2410-8286.151271

[4] A. Özerem, B. Akkoyunlu. Learning environments designed according to learning styles and its effects on mathematics achievement. Eurasian Journal of Educational Research, Vol. 61, 61-80, 2015. doi.org/10.14689/ejer.2015.61.4

[5] T. Derkach. Preferred Learning Styles of Students Majoring in Chemistry, Pharmacy, Technology and Design. Advanced Education, Vol. 9, 55-61, 2018. doi.org/10.20535/2410-8286.131078

[6] Z. Dörnyei. The Psychology of the Language Learner Individual Differences in Second Language Acquisition. Lawrence Erlbaum Associates, Publishers Mahwah, New Jersey, London, 2005.

[7] N. Saienko. Cognitive development of students in foreign language acquisition. Advanced Education, Vol. 7, 4-8, 2017. doi.org/10.20535/2410-8286.77570

[8] M. I. Kellner, B. Curtis, T. DeMarco, K. Kishida, M. Schlumberger, C. Tully. Nontechnological issues in software engineering. Proceedings from the 13th International Conference on Software Engineering, pp. 144 146. doi.org/10.1109/icse.1991.130632

[9] B. Curtis. Techies as nontechnological factors in software engineering? Proceedings from the 13th International Conference on Software Engineering, 147-148, 1991, doi.org/10.1109/icse.1991.130633

[10] G. Matturro, F. Raschetti, C. Fontan. Soft Skills in Software Development Teams: A Survey of the Points of View of Team Leaders and Team Members. 2015 IEEE/ACM 8th International Workshop on Cooperative and Human Aspects of Software Engineering, 101-104, 2015. doi:10.1109/chase.2015.30

[11] R. Elizalde, S. Bayona. Interpersonal Relationships, Leadership and Other Soft Skills in Software Development Projects: A Systematic Review. Trends and Advances in Information Systems and Technologies, 3-15, 2018. doi:10.1007/978-3-319-77712-2_1

[12] C. Sadowski, T. Zimmermann, (eds.). Rethinking Productivity in Software Engineering. Berkeley: CA Apress, 2019. doi:10.1007/978-1-4842-4221-6

[13] B. W. Boehm. Software Engineering Economics, NJ: Prentice-Hall, Inc., Englewood Cliffs, 1981.

[14] E. J. Hargreaves, D. E. Damian. Can global software teams 
learn from military teamwork models? Proceedings from "Third International Workshop on Global Software Development (GSD 2004)" W12S Workshop - 26th International Conference on Software Engineering. 2004. doi.org/10.1049/ic:20040307

[15] M. Hoegl, H. G. Gemuenden. Teamwork Quality and the Success of Innovative Projects: A Theoretical Concept and Empirical Evidence. Organization Science, Vol. 12, No. 4, 435-449, 2001. doi.org/10.1287/orsc.12.4.435.10635

[16] S. M. Samarasinghe, S. U. Samarasinghe, (). Factors Influencing Team Performance in Software Development Projects. American Scientific Research Journal for Engineering, Technology, and Sciences (ASRJETS), Vol. 56, No. 1, 86-103, 2019. doi.org/10.31357/fmscmst.2016.00252

[17] M. B. Pinto, J. K. Pinto. Project team communication and cross-functional cooperation in new program development. Journal of Product Innovation Management, Vol. 7, No. 3, 200-212, 1990. doi.org/10.1016/0737-6782(90)90004-x

[18] A. G. Rezler, V. Rezmovic. The Learning Preference Inventory. Journal of Applied Health, Vol. 10, No. 1, 28-34. 1981.

[19] S. W. Reichman, A. F. Grasha. A rational approach to developing and assessing the construct validity of a study learning style scales investment. Journal of Psychology, Vol.
87, 213-223, 1974.

[20] R. M. Belbin. Team Roles at Work. Routledge, 1st ed. Amsterdam, Pfeiffer, San Diego, 1981.

[21] R. M. Belbin. Team Roles at Work, 2nd ed., Routledge, London, 2010.

[22] B. L. Leaver. Metodika individualizirovannogo obucheniya inostrannomu yazyku s uchetom vliyaniya kognitivnyh stilej na process ego usvoeniya [The methodology of individualized teaching a foreign language with the influence of cognitive styles on the process of learning]. (Dissertaciya kand. ped. nauk). Gosudarstvennyj institut russkogo yazyka im. A. S. Pushkina, Moskva, Rossijskaya Federaciya, 2000.

[23] O. A. Kondrashihina. Differencialnaya psihologiya [Differential Psychology]. Kiev: Centr uchebnoj literatury, 2009.

[24] N. I. Formanovskaya. Rechevoe vzaimodejstvie: kommunikaciya i pragmatika [Speech Interaction: Communication and Pragmatics]. Moscow, IKAR, 2007.

[25] E. Salas, T. L. Dickinson, S. A. Converse S. I. Tannenbaum. Toward an understanding of team performance and training. In R. Swezey \& E. Salas (Eds.), Teams: Their Training and Performance (pp. 3-29). Norwood, NJ: Ablex Publishing Corporation, 1992. 